\title{
Using electromagnetic radiation to power autonomous sensors
}

\author{
Aleksandr Timoshenko ${ }^{1, *}$ and Aleksandr Savochkin ${ }^{1}$ \\ ${ }^{1}$ National Research University of Electronic Technology, Telecommunication Systems Department, \\ 124498 Shokin Square 1, Moscow, Russia
}

\begin{abstract}
The results of calculation and experimental determination of available power are presented. Power sources of autonomous sensors when exposed to electromagnetic radiation with wavelengths in decimeter and centimeter ranges. The experimental values of the parameters of the field models of antennas and electromagnetic radiation receivers designed to power autonomous sensors. The requirements for energy consumption and power supply of autonomous sensors are formulated.
\end{abstract}

\section{Introduction}

In recent years, certain successes have been achieved in the study of autonomous power sources for non-volatile devices. Traditional autonomous power sources, such as solar cells or wind generators, are not always suitable for powering autonomous sensors and similar devices due to their inherent limitations [1-3]. Therefore, power sources using electromagnetic radiation of relatively long wavelength ranges are of great practical interest. These limitations are shown in Table 1 below.

Table 1. Power sources limitations.

\begin{tabular}{|c|c|c|}
\hline Source & Advantages & Limitations \\
\hline Light & $\begin{array}{l}\text { DC-ready circuits, } \\
\text { simplicity, popularity }\end{array}$ & $\begin{array}{l}\text { Fragility, dependence on the presence } \\
\text { of light, the complexity of deployment }\end{array}$ \\
\hline Airflow & $\begin{array}{l}\text { Time-of-day } \\
\text { independence }\end{array}$ & $\begin{array}{l}\text { In a first approximation, a power-law } \\
\text { dependence on fluctuations in airflow. } \\
\text { The presence of moving parts. }\end{array}$ \\
\hline $\begin{array}{l}\text { Movements and } \\
\text { vibrations }\end{array}$ & $\begin{array}{l}\text { Compact circuitry, } \\
\text { high voltage }\end{array}$ & $\begin{array}{l}\text { Charge leakage, depolarization, } \\
\text { frequent power changes }\end{array}$ \\
\hline $\begin{array}{c}\text { Temperature } \\
\text { gradient }\end{array}$ & $\begin{array}{c}\text { Low maintenance cost, } \\
\text { high scalability }\end{array}$ & $\begin{array}{c}\text { The relatively rare availability of a } \\
\text { suitable temperature difference }\end{array}$ \\
\hline Magnet fields & $\begin{array}{l}\text { Simple circuitry and } \\
\text { high transmitted power }\end{array}$ & Low energy transfer distance \\
\hline $\begin{array}{l}\text { Electromagnetic } \\
\text { radiation }\end{array}$ & $\begin{array}{l}\text { Abundant in urban } \\
\text { environments }\end{array}$ & Low power flux density \\
\hline
\end{tabular}

*Corresponding author: tcs@miee.ru 


\section{Objects of research and experimental technique}

\subsection{Objects and tools}

The objects of research were schemes for converting high-frequency oscillations into the direct current as well as efficient circuitry modeling and measurement techniques. Circuitry solutions were modeled using LTSpice suite and tested on mock-ups made using the publicly available range of Schottky diodes with small required bias. Also, methods of increasing energy transfer and conversion effectiveness were researched.

Operating frequency ranges were determined using a spectrum analyzer. The characteristics of antennas and circuit models were measured using a vector analyzer and an RF generator. The efficiency of converting electromagnetic waves into direct current was determined by an RF generator with an output signal level of -60 to $-5 \mathrm{dBm}$. Antennas were modeled using the moment method in the MMANA-GAL ${ }^{\dagger}$ program. Also, the electric field strength preliminary estimation using MMANA-GAL was performed.

\subsection{Method for determining the applicability of radiofrequency power supplies}

The calculation-experimental method for determining the degree of applicability of radiofrequency power sources developed includes the following main elements: measuring the level of available radiation power of electromagnetic waves; determination of the possibility of operation of the power supply circuit with a specific type of antenna; measurement of the accumulation time of the required charge on a buffer capacitor, statistical processing of the results.

Initially, the electric field strength was simulated by the moment method in the MMANA-GAL program. It was figured out that the order of values of electromagnetic field strength was estimated correctly, however exact values of available power could be estimated this way in the near field only. Also, it was cleared out that MMANA-GAL makes it easy to calculate the currents induced in the conductor, but it is difficult to determine the characteristic impedance of the voltage converter by modeling, so the input voltage can only be estimated on the model as a likely range of values. The difficulty in determining the characteristic impedance of the converter is explained by the fact that the characteristics of the printed circuit board topology influence at the converter input impedance on given frequencies.

Measurements were taken in an office building, in an industrial zone, and residential buildings. The measurements were carried out on 5 frequency ranges using a spectrum analyzer with a measuring antenna, in 14 locations total. The frequency ranges were selected based on the assumption that cellular or Wi-Fi is operating in the vicinity of the location of the wireless sensor. Based on the measurements obtained data on the available power of the electromagnetic field, are given in table 2 .

\subsection{Circuitry modeling and actual parameters measuring}

It was found that SPICE modeling allows to reliably predict the dependence of the voltage multiplication coefficient on the number of stages. However, it was also found that the SPICE models of some diodes do not adequately describe the initial portion of the I $-\mathrm{V}$ curve, which makes it impossible to reliably evaluate the sensitivity of the converter. Also, as mentioned above, circuit simulation as a whole does not allow reliable determination of the input impedance of a converter made on discrete components. Thus, it seems

${ }^{\dagger}$ http://gal-ana.de/basicmm/ru/ (accessed 30 September 2019). 
appropriate to use the simulation only at the preliminary stage, after which the simulation results should be verified by a full-scale experiment. One of the test schematic and modeling results are shown in Figures 1 and 2.

Table 2. Available power measurements.

\begin{tabular}{|c|c|c|c|c|c|}
\hline Location & $2.6 \mathrm{Ghz}$ & $2.4 \mathrm{Ghz}$ & $2.1 \mathrm{Ghz}$ & $1.8 \mathrm{Ghz}$ & $928.2 \mathrm{Mhz}$ \\
\hline 1 & $-50 \mathrm{dBm}$ & $-32 \mathrm{dBm}$ & $-48 \mathrm{dBm}$ & $-42 \mathrm{dBm}$ & $-40 \mathrm{dBm}$ \\
\hline 2 & $-54 \mathrm{dBm}$ & $-39 \mathrm{dBm}$ & $-48 \mathrm{dBm}$ & $-43 \mathrm{dBm}$ & $-45 \mathrm{dBm}$ \\
\hline 3 & $-52 \mathrm{dBm}$ & $-42 \mathrm{dBm}$ & $-46 \mathrm{dBm}$ & $-42 \mathrm{dBm}$ & $-43 \mathrm{dBm}$ \\
\hline 4 & $-54 \mathrm{dBm}$ & $-40 \mathrm{dBm}$ & $-47 \mathrm{dBm}$ & $-40 \mathrm{dBm}$ & $-42 \mathrm{dBm}$ \\
\hline 5 & $-60 \mathrm{dBm}$ & $-58 \mathrm{dBm}$ & $-57 \mathrm{dBm}$ & $-55 \mathrm{dBm}$ & $-48 \mathrm{dBm}$ \\
\hline 6 & $-55 \mathrm{dBm}$ & $-65 \mathrm{dBm}$ & $-52 \mathrm{dBm}$ & $-53 \mathrm{dBm}$ & $-47 \mathrm{dBm}$ \\
\hline 7 & $-52 \mathrm{dBm}$ & $-65 \mathrm{dBm}$ & $-47 \mathrm{dBm}$ & $-57 \mathrm{dBm}$ & $-45 \mathrm{dBm}$ \\
\hline 8 & $-45 \mathrm{dBm}$ & $-64 \mathrm{dBm}$ & $-63 \mathrm{dBm}$ & $-46 \mathrm{dBm}$ & $-45 \mathrm{dBm}$ \\
\hline 9 & $-63 \mathrm{dBm}$ & $-49 \mathrm{dBm}$ & $-63 \mathrm{dBm}$ & $-57 \mathrm{dBm}$ & $-63 \mathrm{dBm}$ \\
\hline 10 & $-60 \mathrm{dBm}$ & $-65 \mathrm{dBm}$ & $-49 \mathrm{dBm}$ & $-46 \mathrm{dBm}$ & $-58 \mathrm{dBm}$ \\
\hline 11 & $-59 \mathrm{dBm}$ & $-63 \mathrm{dBm}$ & $-62 \mathrm{dBm}$ & $-57 \mathrm{dBm}$ & $-48 \mathrm{dBm}$ \\
\hline 12 & $-63 \mathrm{dBm}$ & $-63 \mathrm{dBm}$ & $-63 \mathrm{dBm}$ & $-61 \mathrm{dBm}$ & $-49 \mathrm{dBm}$ \\
\hline 13 & $-65 \mathrm{dBm}$ & $-64 \mathrm{dBm}$ & $-62 \mathrm{dBm}$ & $-53 \mathrm{dBm}$ & $-49 \mathrm{dBm}$ \\
\hline 14 & $-65 \mathrm{dBm}$ & $-65 \mathrm{dBm}$ & $-63 \mathrm{dBm}$ & $-58 \mathrm{dBm}$ & $-48 \mathrm{dBm}$ \\
\hline
\end{tabular}

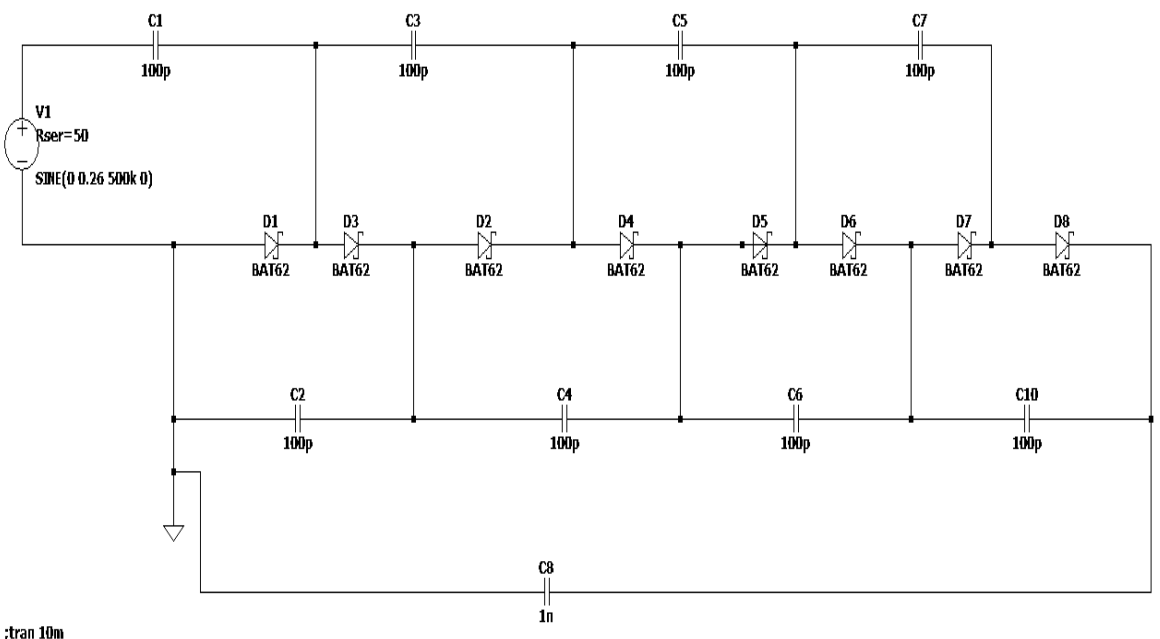

Fig. 1. Test circuit model in LTSpice. 


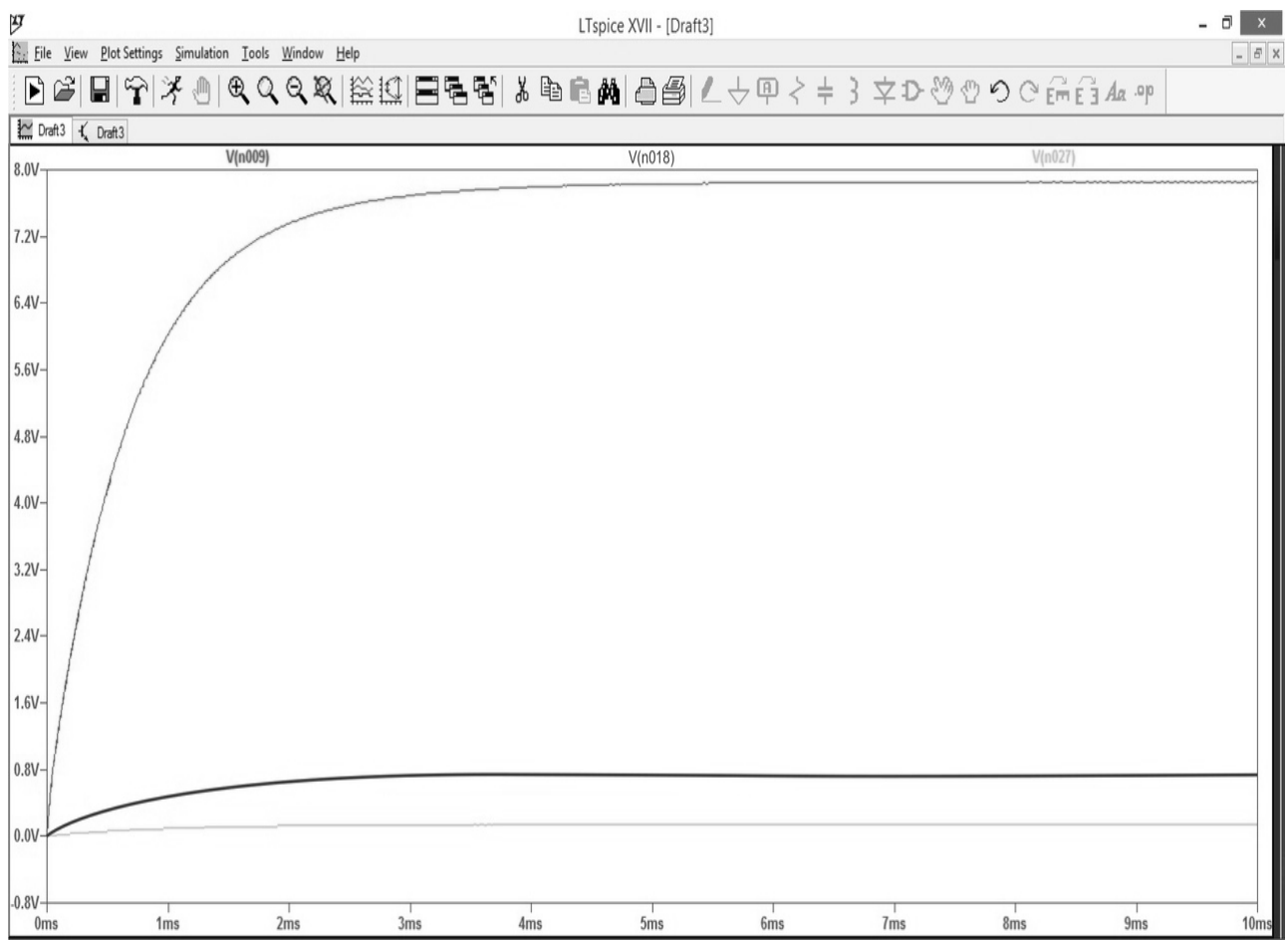

Fig. 2. Input and output voltage.

It was also found to be difficult to simulate a circuit with the accumulation of charge in a large capacitor, since the end of the transition process, even in a full-scale experiment, can be last for tens of minutes. Under such circumstances, the simulation system quickly goes beyond computational capabilities.

Sensitivity measurements were carried out using a high-frequency generator Rohde\&Schwartz SML-03 while feeding the converter via a pre-measured coaxial cable. Test devices were based on Infineon BAT-62 Schottky diodes and low leakage Epcos electrolytic capacitor. During the measurements, the minimum voltage required to start the accumulation of charge on the storage capacitor was determined. The first experiments showed that the circuit has sufficient sensitivity to receive radio emission from spurious antennas formed by tracks on a printed circuit board. Also, measurements showed the need for protection against interference, since their level in most cases exceeded the level of the measuring signal. Also, the experiments showed the performance of the diodes at voltages less than indicated by the graph of the I - V characteristic in the diode datasheet. The relationship between the output voltage of the generator and the voltage at the storage capacitor after a given period was also determined. At an input power of $0 \mathrm{dBm}$, the voltage across the $10 \mathrm{mF}$ storage capacitor was $4.37 \mathrm{~V}$ within an accumulation time of 10 minutes.

During the measurements with antennas, it was found that it is possible to accumulate a charge at which the voltage across the storage capacitor reaches $667 \mathrm{mV}$. It's enough voltage level to power up DC-DC converter. For these measurements, loop band antennas with calculated antenna gain $3 \mathrm{dBi}$ matched to $50+\mathrm{j} 0$ ohms were used.

To evaluate the matching of the antennas with the input of the converter, the input impedance was measured. The measurements used converters made on the same printed circuit boards and using the same components, but with a different number of multiplication cascades. The results of input impedance measurements are in Figures 3 and 4 . 


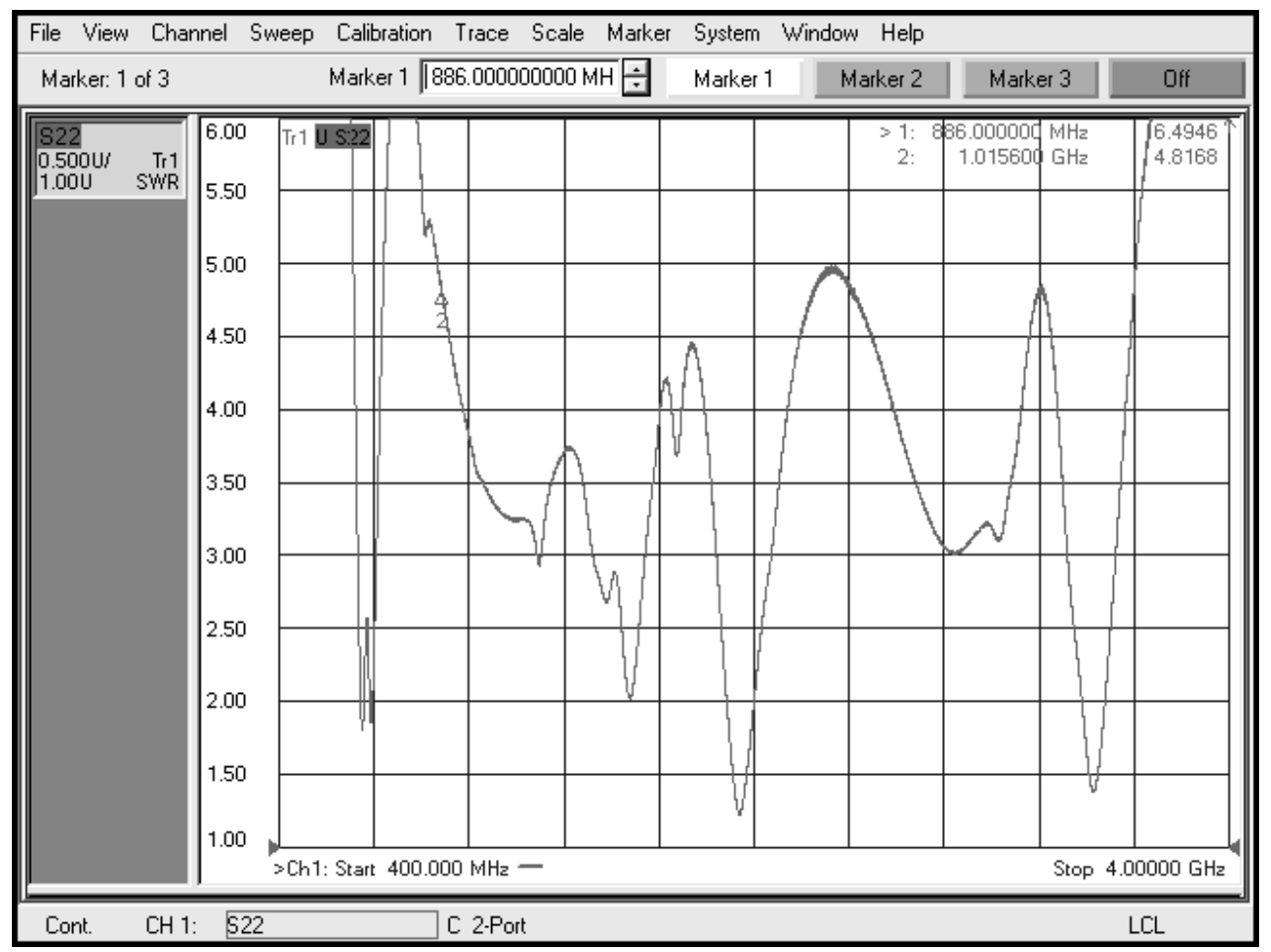

Fig. 3. S22 parameter for 2 cascade converter.

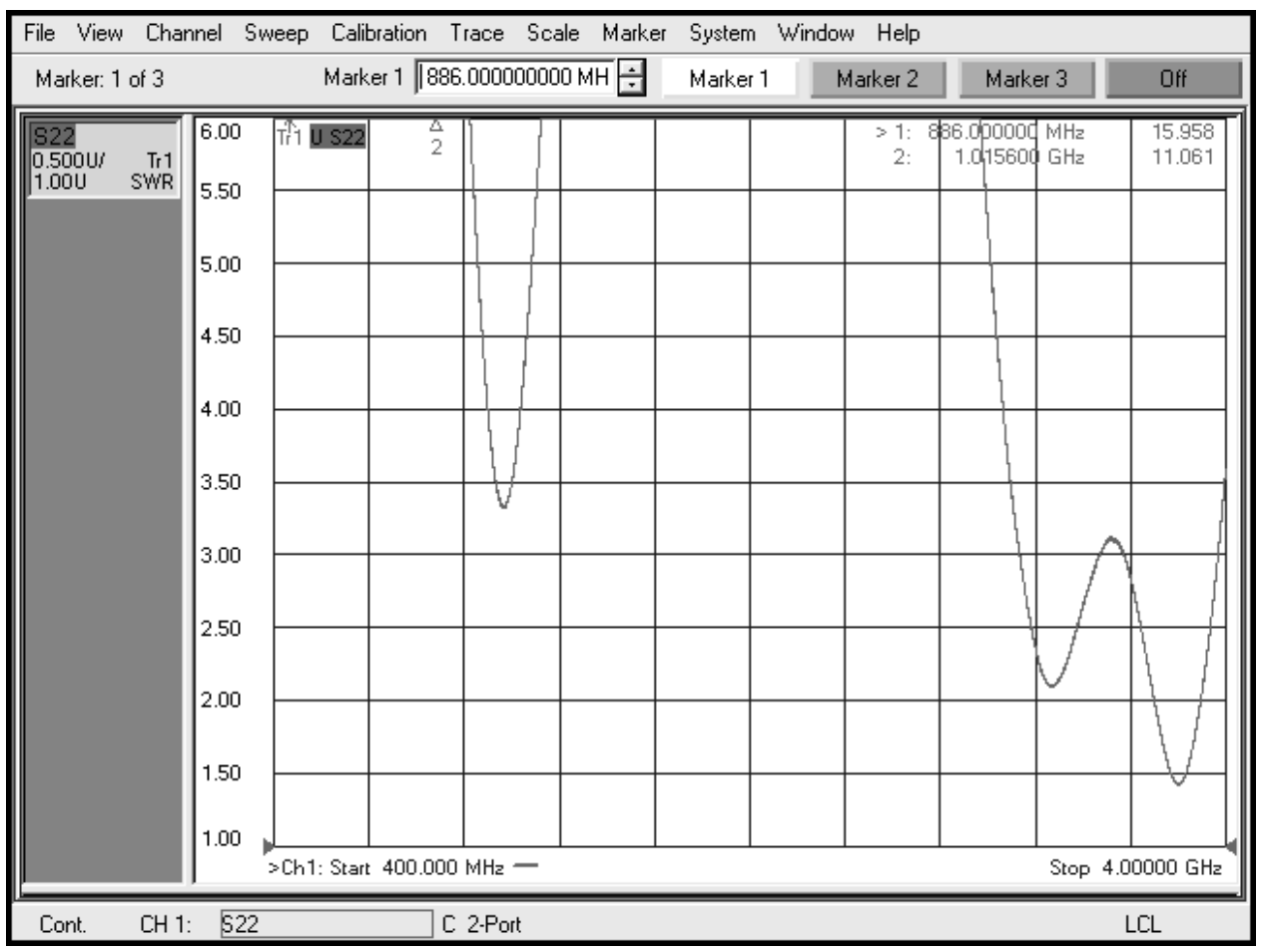

Fig. 4. S22 parameter for 8 cascade converter. 
It can be seen from the figures that the reflection coefficient at the input depends on the number of cascades of multiplication, and the input impedance of the converter needs to be matched with the antenna. In this case, the impedance depends both on the circuit and on its specific hardware implementation.

Experiments with hardware mock-ups showed that it is advisable to perform converters with the number of multiplication stages from 2 to 8 . At the same time, increasing the number of multiplication stages reduces the charging current and increases the charge accumulation time on the capacitor, but also increases the voltage to which the storage capacitor is charged. An increase in multiplication cascades to 16 in practical measurements showed that the voltage drop across the diodes compensates for the voltage increase, as a result of which the efficiency of the multiplier decreases until the complete loss of efficiency. It is unnecessary to mention that the leakage current of the storage capacitor should be as small as possible. In this study, the leakage current of the storage capacitor was not measured, but experiments with different capacitors showed that it is possible to find a capacitor that is unable to accumulate charge at all in a given circuit.

It is known that the received radio emission power is described by equation (1).

$$
P_{R x}=P_{T x} \frac{G_{T x} G_{R x} \lambda^{2}}{(4 \pi d)^{2} L}
$$

where

$$
\begin{aligned}
& P_{R x}-\text { received power, } \\
& P_{T x} \text { - transmitted power, } \\
& G_{T x} \text { - transmit antenna gain, } \\
& G_{R x} \text { - receive antenna gain, } \\
& \lambda \text { - wavelength, } \\
& d-\text { the distance between antennas, } \\
& L \text { - path loss coefficient. }
\end{aligned}
$$

From equation (1) it follows that in the context of using radio emission to power autonomous sensors, it is possible to affect only the gain of the receiving antenna and the distance between the receiving and transmitting antennas. Therefore, it seems appropriate to use antennas with a pronounced directivity, if possible, which obviously allows increasing the rate of charge accumulation. For example, an antenna with a gain of $10 \mathrm{dBi}$ in comparison with an isotropic antenna allows you to get a voltage gain of about 3 times.

When choosing a circuitry solution taking into account the available radio emission power, it seems appropriate to proceed from a compromise between the charge accumulation rate, the output voltage, the sensor operating time and its current consumption, as well as the ability to install an antenna with a given gain.

\section{Future works}

It is planned to study the applicability of radio frequency oscillations in the range from 100 $\mathrm{kHz}$ to $5 \mathrm{MHz}$ for powering autonomous sensors. It seems reasonable to investigate this range because the noise level under Recommendation ITU-R P.372-11 [4] in the indicated frequency range by power exceeds the values available in the microwave range. This circumstance gives reason to believe that it is possible to organize the power supply of such sensors far from artificial sources of radio emission, which makes it possible to use autonomous sensors in industries such as agriculture and environmental protection. Besides, it is planned to investigate the applicability of electrical oscillation transducer circuits in combination with mechanical vibration sensors such as hydrophones and piezoelectric transducers. This, in turn, makes it possible to organize the supply of autonomous sensors from sources of mechanical vibrations and acoustic noise. 


\section{Conclusion}

A calculation and experimental method were proposed for predicting the determination of the degree of applicability of radiofrequency power supplies, including measuring the available power of electromagnetic radiation; selection of the optimal antenna and circuitry of the converter based on diodes with low or zero required bias. The levels of available power of electromagnetic radiation necessary for the operation of radio-frequency power sources in various frequency ranges with a given efficiency are determined. Receiving antennas suitable for working with radiofrequency energy sources have been developed, taking into account various restrictions on the placement of such sources. For developers of autonomous sensors, recommendations are given for choosing an operating mode based on the level of available electromagnetic radiation power at the sensor installation site.

The authors are grateful to Andrei Tikhomirov for valuable advice on general issues of radio engineering, to Maxim Sokolov for help in organizing and conducting measurements, and to the entire team and the leadership of the Department of Telecommunication Systems of the Moscow Institute of Electronic Technology for comprehensive support during this study.

\section{References}

1. K. Wu, D. Choudhury, H. Matsumoto Wireless power transmission, technology, and applications // Proc. IEEE. Vol. 101. No. 6. P. 1271-1275 (2013)

2. R.V. Christopher, D. D. Gregory, Harvesting Wireless Power // IEEE paper. P. 1-2 (2014)

3. B. C. Nuno, A. Georgiadis, A. Costanzo Wireless Power Transmission: R\&D Activities Within Europe // IEEE Transactions on Microwave Theory and Techniques. Vol. 62 (2014)

4. ITU P.372-14: Radio noise 